\title{
Research on the Beauty of Art Animation
}

\author{
Weina Sheng \\ Weinan Normal University, Weinan, Shaanxi, 714000, China
}

Keywords: Art Animation; Diverse Forms; Philosophical Thinking; Poetic Language; Freedom of the Environment

\begin{abstract}
In addition to the universal characteristics of animated works such as creativity, exaggeration, fun and humor, the art animation has strong individuality and avant-garde in the pursuit of art, which is experimental, original and exploratory. This article elaborates the difference between art animation and commercial animation, and focuses on the aesthetic features such as diverse forms of art animation, philosophical thinking, poetic language and freedom. It is necessary to have creative thinking, comprehensively and profoundly understand and comprehend these aesthetic characteristics of the art animation to summarize the "implied meaning" and "taste outside the taste" of the art animation.
\end{abstract}

\section{Overview of Art and Animation}

Animations are the artistic effects produced by industrial arts, such as art, synthesis of literature, painting, music, performance, photography and other artistic means. The animations are achieved through exaggeration, deformation, fantasy, fiction and surreal. The spirituality of the animation is that it has the wings of dreams and flies in the paradise of dreams. It surpasses reality and transcends life and has the artistic expression above the reality. The performance of people's lives, emotions, ideals, aspirations, its exaggerated expressive language can not be separated from the use of animations. The animated exaggeration is manifested in the non-realism of the creative technique, which is constructed through the unique language of the animation. For instance, in a paper animation entitled "Passion on Paper", which won the 2013 Oscars for best animated short film, the paper was given life and led the protagonist to pursue the exaggeration of love.

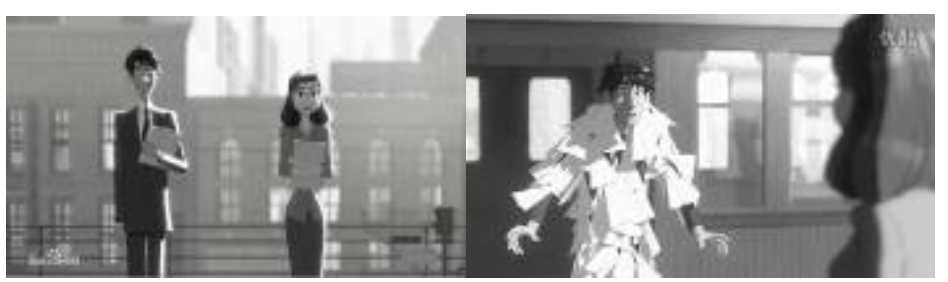

Figure 1 US animation "paper talk" screenshot

Animations are broadly divided into commercial animations and art animations by type, while the difference between animations and commercial animations lies in the greater freedom of creation, the more diversified techniques of production, and the greater artistic performance and experimentation. In addition to its general characteristics of animated creativity, exaggeration, interest and humor, art animation has a strong personality and avant-garde in the pursuit of art. "Compared to commercial animations, 'paintings' in art animations seem to be more freely borrowed and transplanted into the art of painting and other forms of art making the animations more colorful, artistic and interesting." [1] People call commercial animation "cartoon movies" and art animation "art movies." In a word, art animation tends to exert its noumenon on the connotation of form more, while commercial animation tends to interpenetrate multi-culture. Art animation is a dynamic presentation of creator's artistic conception and ideology. It has the characteristics of experimentation, originality and exploration. It is often attempted and creatively applied in the form of pictures and the use of audio-visual language. Art animation can be " Cognition and regularity, and enjoy the artist's personalized original charm and ideology "[2]. Is an individualized existence 
of animation with more in-depth exploration in terms of content and presentation, breaking through the production paradigm of traditional animations, having various forms of expression, having a vast space for expression, having magical artistic charm and aesthetic taste, ideological and artistic High, requires creators with a high artistic accomplishment and creative experience, as well as rich imagination and superb artistic expression. Because of its short, so the creators need a limited time for a high degree of generalization and refine exaggeration, to convey its profound thoughts and rich emotions.

\section{The Aesthetic Characteristics of Art Animation}

Animation language is the fantasy brush of animators, through the conciseness of art at multiple levels such as formal language, image language and implication expression. Regardless of the animation modeling language, the animation narrative language and animation language have the characteristics of virtuality, narrative performance, generalization, exaggeration and sports rhythm. Animation art with its unique image to create, people feel fresh and interesting. That is because those who through the artist's fantasy to create all kinds of animated images are all human nature and human enrichment, refining, exaggeration and sublimation, on a real basis into the dramatic creation. But not all distinctive personality, and some even very vague, the animated world is not necessarily the clear and clear soul hometown. Pure and warm are not unique charm of art animation, in the simple and warm from time to time will hide the dangerous and heavy meaning. Animated themes, manifestations with the development of society, become more and more diverse. No matter the image is created, the theme is set, the picture style does not have certain rules. For example, in the head-down animation of head-to-head animation directed by Timothy Rupert, a British director and screenwriter, actor Walt lives on the floor while actress Machie lives on the ceiling. This exaggeration the full expression of drama embodied in the animation vividly.

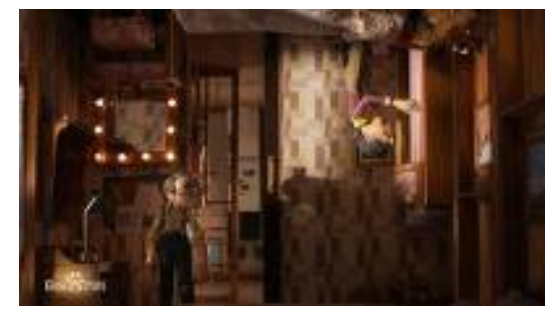

Figure 2 British animation "head-down life" screenshot

In order to reflect the creators' individualized ideas and ideas, the creative work of art is characterized by its innovative features. Therefore, it has diversified forms. In addition to the collection of sketches, sketches, hook line coloring, ink painting, oil painting, watercolor, gouache, Drawing, printing and other two-dimensional drawing language and three-dimensional computer-made language, the sand, metal parts, glass, plasticine, cloth, paper stickers and other materials collage material practices and photography making real use of experimental animation The form is very diverse, is a variety of materials, a variety of production forms of the collection.

In creating the ink-style animated cartoon "Muti," artist Lee Ke-dyed drew 14 paintings of water buffalo and shepherd boy for reference. Hemingway's masterpiece "The Old Man and the Sea" made by Russia's Alexander Petrov is the artist's painterly paint on glass with finger paint.

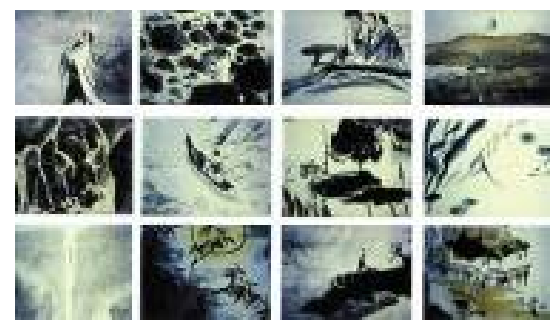

Figure 3 Chinese animation "Manifesto" screenshots 


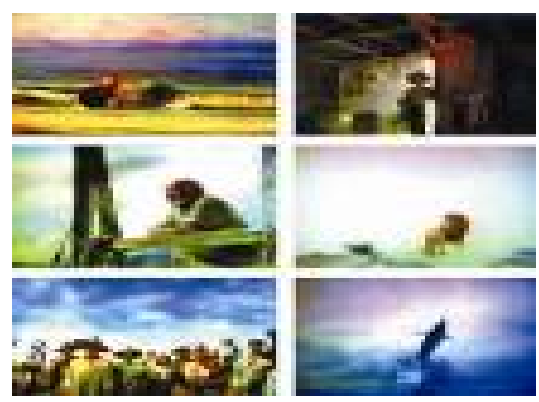

Figure 4 Russian animation "The Old Man and the Sea" screenshot

Colored pencils can give the viewer a rustic feel of warmth, while the crayon's thick brushstrokes have a special, naive aesthetic. The three main creators of French animated "Plain Days" are represented by computer-simulated crayons while the "Frog's Fables" are drawn using crayons and oil swabs.

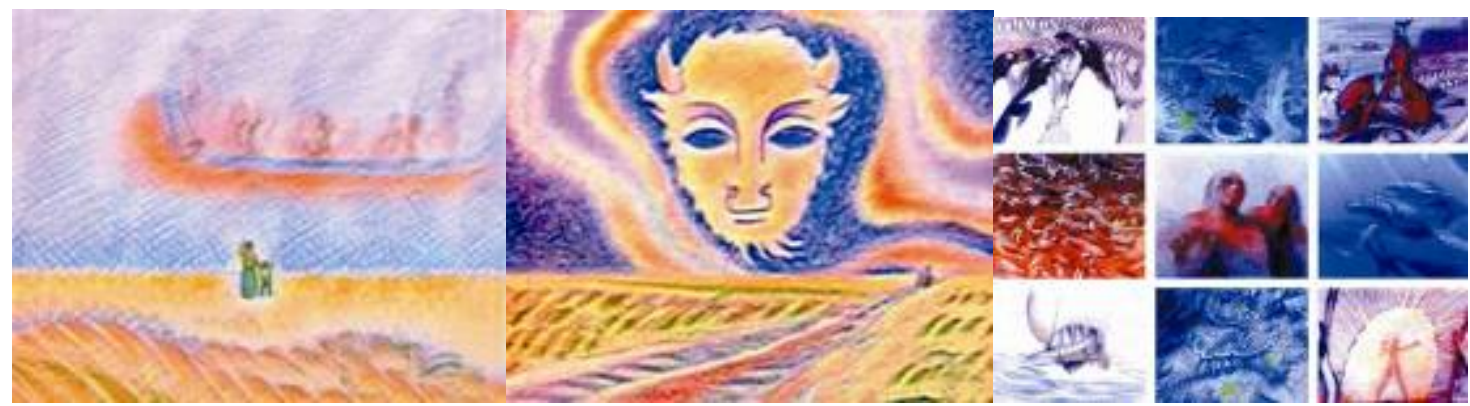

Figure 5 French animation "plain days" screenshot
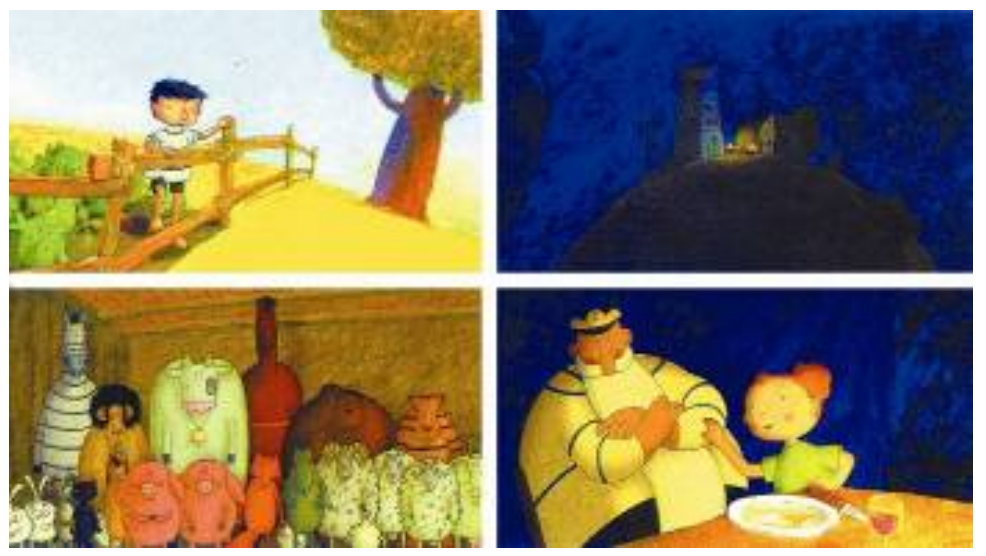

Figure 6 French animation "Frog Fables" screenshot

Famous French animation artist Fredrik Bach's work "wooden rocking chair", in order to show the complex atmosphere of the environment, fresh and bright, rich and exquisite color effects, finely depict the texture of the image texture with wonderful chalk creation means, Express its unique humane care.
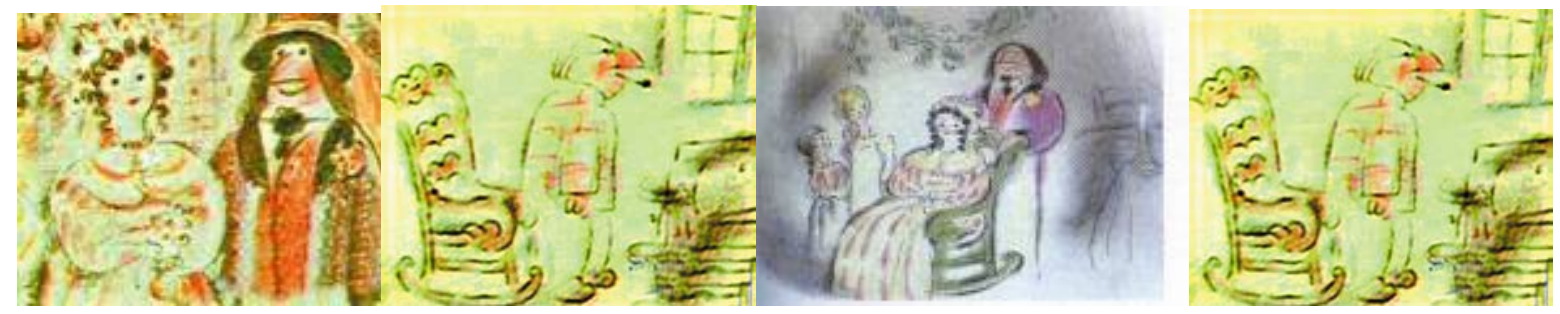

Figure 7 French animation "wooden rocker" screenshot 


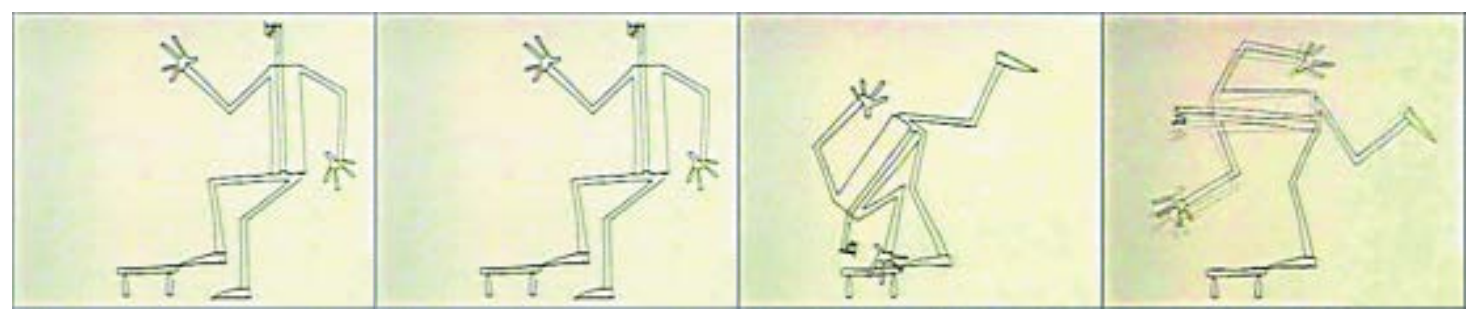

Figure 8 French animation "noodles" screenshot

1986 Cannes Film Festival exhibition "dry noodles" is animated artist Don. Collins use line drawing techniques to complete the work. Screen using a single outline, with a simple and powerful feeling.

Russian animation artist Balladin created the animation "The hit of the traveler" is created by the creators using steel wire.

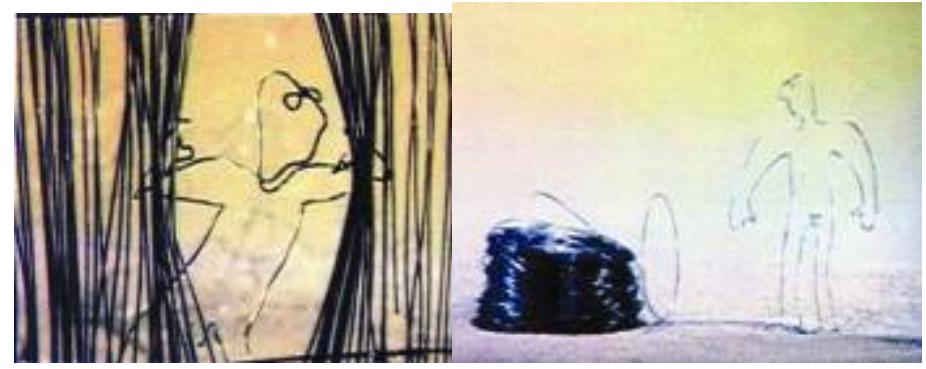

Figure 9 French animation "traveler's hoop" screenshot

"Candy Gymnastics" Joan Glees and Joanne Price Gallery and ten animators from different countries, with candy, chocolate directly to do the material collage assembled, bringing the viewer a wealth of visual Experience.

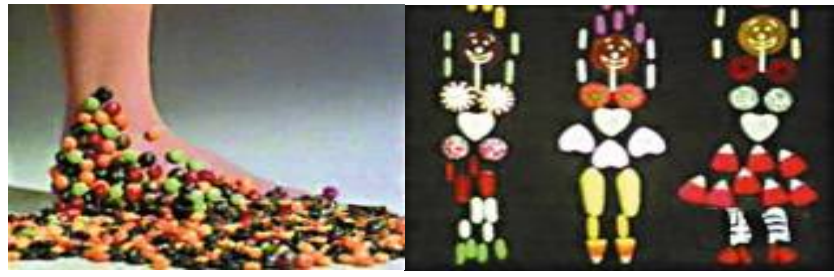

Figure 10 French animation "candy gymnastics" screenshots

Animated "Two Sisters" Canadian female anime director Caroline Reeve uses art sketches of egg yolk and glue instead of paint to create a delicate representation of complex emotions.

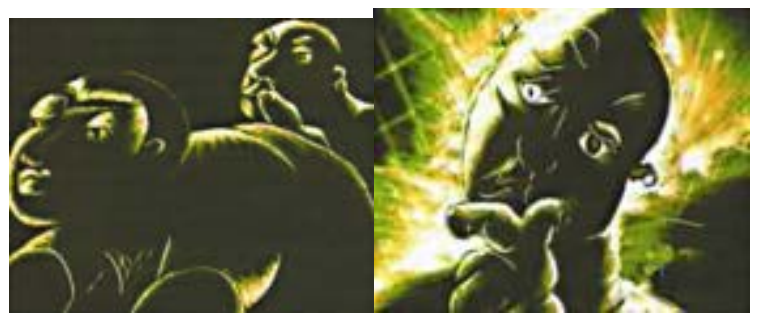

Figure 11 Canadian animation "two sisters" screenshots

In short, with the constant exploration and creation of animation artists, the performance forms of the animated cartoon show more and more new forms, the manifestations are continuously updated and the creative space is also expanding indefinitely. However, the form innovation of the art animation is to a certain extent It also broadened the art of commercial animation.

Animated art is an expression of animations by the animators using their own "do-not-so-eye" images, as well as the "aura of chaos", or the immaculate simplicity or the samaritability. It is an imaginary world built by animators with their own "intonation." It is not only the flow of the animator's interest, but also the direct flow of the subconscious artist. It is the "visual" and the 
"perceived" created by the animator's thought after the infinite development. This kind of visual care is the multiple fusion of the form and meaning of the "creation environment". However, the representation of animations such as "philosophical thinking and rhyming into metaphysics" is also an expression of the imaginary and non-existent images. Deliberately breaking the norm and performing the exaggerated performance are the paradigms of the animated language. In the context of the animation context, the pragmatic implications of the animations contained therein are deduced, and the sounds outside the strings in this animation is illustrated and understood. This implicit non-direct way of expression, in some philosophical animations Often used. For example, the animated short film "Balance" made by Germany's twin brothers Christoph-Lawenstein and Wolfgang-Raustein, through a square plane suspended in the air, and five standing people The story between a music box, which contains the concept of the German community, the emphasis on stability, balance, the pursuit of a peaceful life, and the resistance to temptation and other ideas.

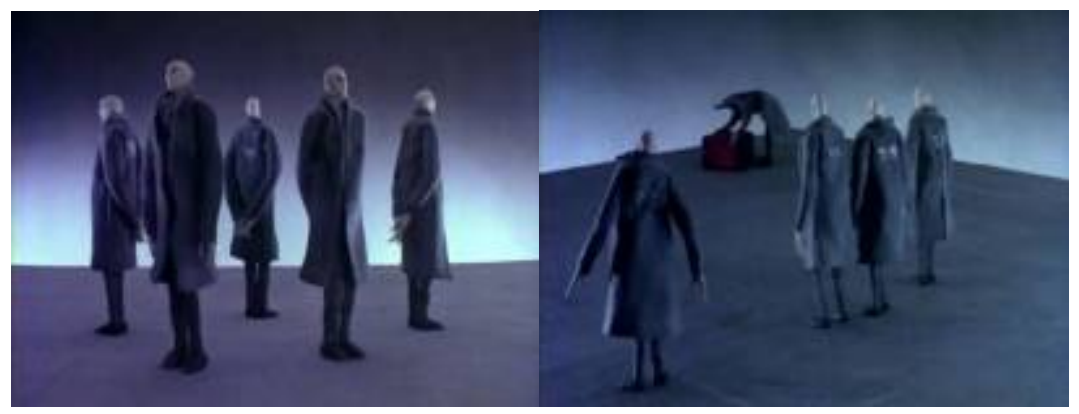

Figure 12 German animation "balance" screenshot

"Art is tens of millions of imaginary, constantly creating thousands of phantom," the same is true art animation. The generation of art animation is the animation artist through a keen artistic intuition, a combination of symbolic shapes, abstract colors and other image symbols. By using the means of perceiving the natural secrets and following the creators' aesthetic thinking rules of expression, they express the natural meaning and the author's consciousness, and then they turn out to be extraordinary from ordinaryity. The construction of all the schemata in the animated works, the expression of the mind, the comprehension of the psychology field are all the biochemical thoughts of the author. These conceptual representations of animation range from visual perception to subjective cognition, and visual perception and conscious feelings are affected by the concept of creator. The concept of creator is constrained by cultural ideals, social customs, moral ethics, ways of thinking and material basis. Creators have different concepts, cognitive styles and performance styles are different, the formation of animated images of the intuitive and non-intuitive style is different. However, the artistic colors presented are based on the cultural concept of "fuzzy integration." Such as the traditional cultural and genetic genes, has long infiltrated the creator's subjective consciousness and mind.

The poetic language of the animation is the symbol of the animation, which is the abstract, the concrete and the image expression of the animators in the creative design of animations to express their own ideas. The presented sentimental performance and rational appearance and the aesthetic realm are the unique ways of thinking and observation of animators' own uniqueness and the aesthetic aesthetic awareness of the unique art. It is a poetic vision presented in a clear, clear, intuitive and free form by the time, space, things, events, past, present and future. From the real and beyond the real, is the aesthetic ideal of creators of animation. The poetic integration of the universe and natural connotation into the language of animation presents an infinite possibility for us to create an infinite space of visual and psychological space for us to offer us unlimited imagination. Is an animation artist's stylistic and stylistic images of diverse animations that are created after the natural, complex nature of body odor, reflection, perception and discrimination of animations, and are the author's imagination of the situation inspired by the spontaneous development of the creatures, as well as the author's breakthrough in the material nature and also The breakthrough of his own strength, with the poetic vision of "placing himself in the boundless spiritual world", is the result of the artist's aesthetic thinking diverging. Such as Kant's "pure form of perceptual intuition"; 
as Jill Deleuze said: "The purpose of art is to distort perceptions from the perception of objects and the state of the subject of perception, State transition to another state of feeling to distort the feeling: to abstract the feeling of agglomeration, the formation of the pure feeling of pure. "Such as the Canadian animated master Frederic Back $<<$ tree planting shepherd $>>$ about the lonely shepherd With its own power, it took decades to plant large stretches of woods in the desert and turn the mound into an oasis, giving the viewer poetic aesthetics and fluidity.

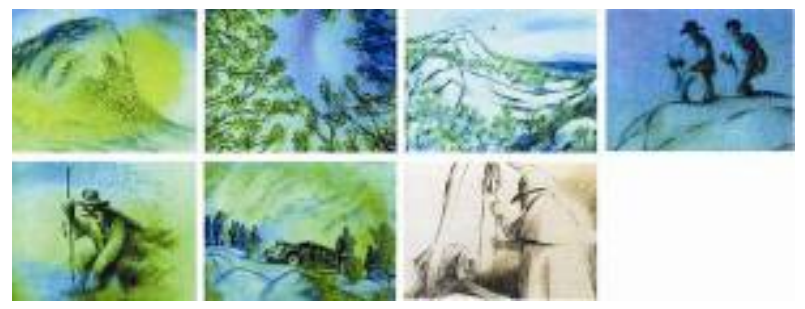

Figure 13 Canadian animation "tree planting shepherd" screenshot

"The first impulse of life points first to the freedom of action." [3] There is no imprisonment in the world of animation, and the mind is free. Unconstrained by the laws of nature, and constantly challenging the ultimate, art animation is an infinite transcendence of objective reality, with its unique super logic to replace the logic of daily life or objective and natural. Can be brighter, "cranky", the only way the animated Civic will be infinitely vast. Any fetters of our free thought and thinking, we can all refuse. Emphasize the taste and imagination, but also do not avoid those overly realistic and complex things, not necessarily to meet the audience's expectations of the film, but the animation of life, but also the drama of life, artistic, we can feel the exaggeration and fantasy. In this exaggerated animation world, everything can become impossible. As animated short film "Hired Workers" directed by Argentine director Santiago Grasso, the whole film has no music, no dialogue, no surprise twists and turns, no outstanding special effects, some humorous expressions, simple and simple techniques, and Imaginative creativity, ordinary, simple story behind the deep emotional content and philosophy of life. View the entire movie, give us only long thinking and aftertaste. Appearing in the film lights, tables, chairs, hangers, cabs, elevators and other common life tools are composed of people, to the last actor in front of someone else's office in the form of a doormat, have a strong drama Effect is the result of free creation in creation.

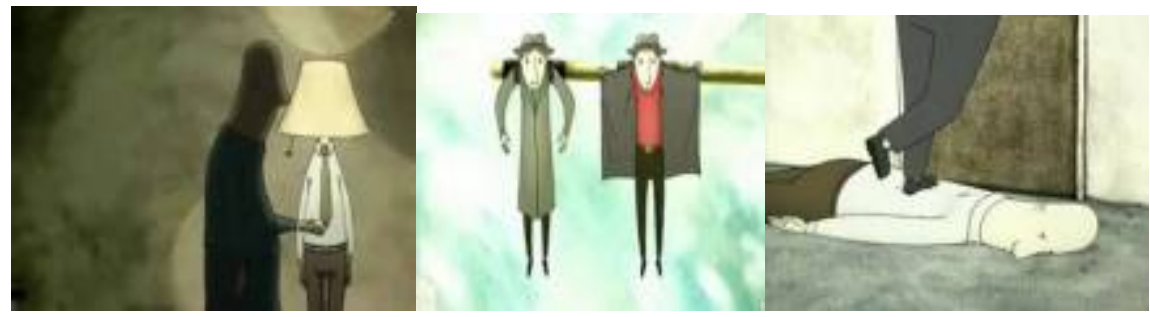

Figure 14 Argentinean animation "Hired Lives" screenshot

The charm of art animation is that it does not follow any fixed patterns, formats and techniques for the exploration of the nature of animation art, with its own unique language expression system. Zhuangsheng Taoism with the naturalistic colors; "Kunpeng wings" beyond the freedom of the space shown in his; without losing the true, leisurely noble spirit of temperament; exudes life philosophy and aesthetic experience of the comfortable atmosphere, Open the door of creativity for us to create animation dreams, to build an animated home for thought-taking. Take us to realize the meaning of life that "heaven and earth merge with me and everything is one with me." Animations need to go beyond the conventional imagination and unique artistic creation to create unique aesthetic experiences that are animated. Animations are the most free form of communication. There are no objective restrictions on performers, cameras and cameras. They find room to breathe in the "illusionary experience and life experience." They are able to express their omnipotence and make our life new. 


\section{Conclusion}

In short, the process of presenting each artwork is also the process of artist's dialogue with his or her own mind. It is influenced by many factors such as artist's personality, life process, self-mood, psychological experience and psychological process, psychological interest and artistic accumulation. At the same time, the artist's creation also needs to have the status and persistent enthusiasm of Shen Jin as well as the realm of being comfortable. Animation works are the artistic creation made by the animators through their communication and connection with objective scenes and subjective scenes and their artistic means. Artistic pursuit and artistic expression are intuitive and expressive. Based on the perception of the object world and the spiritual world, animators only have their own rich emotions and use the means of imagination and thinking to create and express animations. This exploratory and creative process is The fusion of the subject and the object, the process of infiltration and infiltration. Art animation is unique animation language charm and animation humor wisdom to realize the reality of the dream process, sometimes implicit, sometimes sharp, sometimes deep, bring us inspiration, let us aftertaste, to feel and appreciate the art of animation, "the implication It is necessary to have creative thinking. It is necessary to fully and profoundly understand the humorous thinking and exaggeration language of art animation, the diversified forms of perceived art animation in depth, the philosophical thinking, the poetic language and Aesthetics of freedom and other aesthetic characteristics. Animators need to be mentally enshrined in the sky of "Kunpeng" and use poetics and poetry. "It can either be as brutal as a brute force struggle or as big as Kunpeng's wings, giving birth to an ironic or sublime meaning in the exaggerated deformation of the structure of time and space." All species and states can enter a surreal dream space in the change of super logic. Through the animated exaggerated language illusion set free time and space, comfortable environment, with "Tao" concept, thus entering the infinite freedom of the abstract space, create a natural and spiritual vision coexist with the vast visual environment.

\section{References}

[1] Chang Hong. "Art Animation and Commercial Animation"[J]. Jinan: New Art: 2007 No. 4, Page 63

[2] Zhou Tian. "Experimental Animation"[M]. Beijing: China Building Industry Press,2014. Page. 1

[3] Bergson, "The Theory of Creativity" [M]. "Book of Collections", Paris, 1963, p. 711 